\title{
Interaction Milieu Explains Performance of Species in Simple Food Webs along an Environmental Gradient
}

\author{
Jacintha Ellers ${ }^{*}$, André T.C. Dias and Matty P. Berg \\ Department of Ecological Science, Faculty of Earth and Life Sciences, VU University Amsterdam, De Boelelaan 1085, \\ 1081 HV Amsterdam, The Netherlands
}

\begin{abstract}
Species interact with each other in a complex network of relationships that can be modeled as an interaction milieu, i.e. a biotic background with which the species interacts. The interaction milieu is given by the frequency distribution of traits that are important to a given interaction; hence this approach provides a direct link between organism performance, abiotic environmental conditions and interspecific interactions. In this study, we investigate how performance of component species is affected by the interaction milieu along an environmental gradient. We specifically addressed two questions: 1) can the interaction milieu shift species performance away from the niche optimum?, and 2) do species have a higher invasive potential if they have divergent trait values compared to the interaction milieu? We developed a model where a target species showing a given performance response curve to an environmental gradient, i.e., generalist or specialist, interacts with predators and competitors. The predictions of the model were compared with empirical findings on the abundance patterns of species along a salinity gradient in a green beach ecosystem. Green beaches are characterized by their strong gradients and spatial variability in abiotic factors, and their relatively simple food web consisting of Collembola species and their spider predators. First, our results showed that interaction milieu can displace species from their fundamental niche optimum. This led to abundance patterns that cannot be predicted by species performance response curves alone, emphasizing the importance to include ecological interactions. Second, species failed to invade their preferred part of the gradient if predators or competitors shared the target species' preference. Future studies should explore if the concept of interaction milieu can be generalized across trophic levels, and search for traits that are important on deciding the outcome of ecological interactions. Furthermore, the identification of the relevant response traits and their frequency distribution, in combination with trait plasticity of species in interaction milieus might be a step forward to link evolutionary principles to ecological networks, and vice versa.
\end{abstract}

Keywords: Coastal plain, Collembola, food web, fundamental niche, interaction milieu, invasion, phenotypic plasticity, functional traits.

\section{INTRODUCTION}

Ecological communities comprise co-occurring species that interact with each other and with their abiotic environment. This multitude of direct and indirect interactions greatly determines whether a species is able to establish, persist and increase abundance in a given place. This complex network of interactions poses a challenge to formulate general mechanistic rules that shape community structure and, thereby, provide quantitative predictions (Lawton 1999; Simberloff 2004; Lockwood 2008). Since the formulation of the principle of competitive exclusion (Gause 1936), the favored approach on studying the outcome of species interactions, using pairs of interacting species, has failed to address such complexity. Even in relatively simple communities the study of pair-wise species interactions might fail to predict observed patterns of abundance, since interactions are in most cases diffuse (Moran and Hurd 1998) and change with environmental conditions (Johnson et al. 1997;

*Address correspondence to this author at the Department of Ecological Science, VU University Amsterdam, De Boelelaan 1085, $1081 \mathrm{HV}$ Amsterdam, The Netherlands; Tel: 3120 5987076; Fax: 3120 5987123; E-mail: jacintha.ellers@falw.vu.nl

Guest Editor: Dr. Jordi Moya-Larano
Agrawal et al. 2007). Therefore, interspecific interactions mediate the performance of individual species not only directly but also by changing species response to environmental changes (Davis et al. 1998; Jiang and Morin 2004). Accordingly, the interaction between the biotic and abiotic context on shaping community structure has been stressed as a priority research topic (Agrawal et al. 2007).

It has recently been suggested that the effect of interactions on the performance of species can be better understood as an interaction milieu, that is, a biotic background with which the organism interacts (McGill et al. 2006). As originally formulated, the frequency distribution of traits that are important to a given interaction provides an operational definition of interaction milieu. This approach has the advantage of simplifying the network of interactions to a manageable level although other approaches exist to cope with network complexity (e.g., Bascompte et al. 2003, Brose $\&$ Dunne 2009). Moreover, the use of functional traits (sensu Violle et al. 2007) provides a direct link between organism performance, abiotic conditions and interspecific interactions. Although the use of traits can improve our inference about the mechanisms behind the studied interactions, the relation between traits and interactions is still rarely quantified (Falster and Westoby 2003; Eichenberger et al. 2009). This is particularly true for food webs since the traits 
involved in trophic interactions are still not well established (but see Emmerson and Raffaelli 2004; Reiss et al. 2009; Wood et al. 2010). The adoption of a more phenomenological approach can be a good alternative if the mechanisms and traits involved in the studied interaction are not well established. The overall interaction strength (e.g., competition or predation pressure) can be estimated in various ways (Berlow et al. 2004), for example by experimentally excluding competitors or predators; or by recording the density of competitors or predators involved in the interaction, assuming that the different species present in the community have similar impact on the target species.

To understand how community composition affects performance of the component species, the notion of fundamental and realized niche is essential and can best be studied along an abitoic environmental gradient. The reaction norm of a fitness parameter (performance response curve) along an environmental gradient can be seen as a representation of species fundamental niche. Interactions, however, can displace species from the part of the gradient where they perform better. For instance, a bio-energetic model constructed by Buckley and Roughgarden (2005) was able to explain abundance patterns of Anolis lizards in elevation gradients on one-species islands. But on islands where two species were present, the abundance pattern diverged from the model predictions, presumably due to competition, with one species being more abundant at lower and the other at higher elevation than predicted. Quantification of the interaction milieu along abiotic environmental gradients provides a general framework explaining why species are not necessarily most abundant at their fundamental-niche optimum (McGill et al. 2006). This also has important consequences for understanding evolutionary processes by placing interaction between community components as an essential selective force determining genetic and phenotypic variation at the individual level, and vice versa, traits of individuals and species as essential to understand and predict community functioning and composition (Johnson and Stinchcombe 2007; Berg and Ellers 2010; Ellers 2010).

The importance of species traits on community functioning can be illustrated by their effect on susceptibility to invasion. This important community property is dependent on the functional identity of both present and potential invasive species (Funk and Vitousek 2007; Funk et al. 2008). For instance, a network model by Romanuk and coworkers (2009) predicted generalist predators to be more successful invaders, although for some trophic categories of invaders the topology of the food web was more important. Biotic interactions and abiotic conditions can be seen as filters that constrain the range of viable ecological strategies in a community and, therefore, the species that are able to invade. Environmental filters will select species with similar functional niche traits (Grime 2006). On the other hand, competition will displace species that exploit resources in a similar way leading to higher trait dissimilarity of cooccurring species (Weiher et al. 1998). The concept of interaction milieu can potentially help to predict when a species is likely to invade a given community, by allowing a comparison of community functional composition with the functional identity of the potential invasive species.
Here, we investigate how performance of component species is affected by the interaction milieu along an abiotic environmental gradient. We developed a model where a target species with a specific performance response curve for an abiotic factor interacts with predators and competitors. In the model, predation and competition pressure can vary with abiotic environmental conditions, leading to predictions on how interaction milieu changes the performance of the target species along the gradient. We specifically addressed two questions: 1) Can the interaction milieu shift species performance away from the niche optimum?, and 2) Do species have a higher invasive potential if they have divergent trait values compared to the interaction milieu? We then compared the model predictions with abundance patterns of species in a soil community along a salinity gradient in a green beach ecosystem.

\section{MATERIALS AND METHODS}

\section{Green Beach Ecosystem}

Green beach ecosystems are defined as the vegetated part of beaches, located in the supra-tidal zone on a height gradient between the dunes and the sea (Van Wingerden et al. 1981; Brown and McLachlan 1990). They arise as the result of newly formed, small dunes, about one meter in height, which are fixed by the grass Elymus farctus. These young dunes collect drift sand and prevent the coastal plain that lay behind the embryonic dunes against sand blows and the normal tide. On such a sheltered coastal plain, microbial mats can establish that stabilize the sand. This sets-off a succession of salt-tolerant plants that do not tolerate drift sand. Green beaches are characterized by their strong gradients and spatial variability in abiotic factors, not only in the percentage of silt in the top soil, but also in soil humidity and salt content (Van Wingerden et al. 1981). Green beaches are irregularly flooded, only when spring tide occurs and often in combination with onshore storms. Inundation with sea water, in combination with elevation differences, groundwater seepage, and rainfall events leads to a gradient in the soil salt content, ranging from areas with (hyper)saline conditions, to brackish and non-saline conditions.

Our study site comprised a salinity gradient in the green beach found along the coastline of the island of Schiermonnikoog, the Netherlands (N53 28'40.8' E6 09'34.5”). The lower part of the green beach is located at the west point of the island. Here, the salt content of the soil can reach sea water values after inundation ( $45 \mathrm{~g} \mathrm{NaCl} \mathrm{l}^{-1}$ soil solution) or higher values when inundation is followed by evaporation. The higher part, located at the north side of the island, is less frequently inundated with sea water, and receives large amounts of seepage water from the adjacent inland dunes. This results in non-saline conditions (soil salt content $2 \mathrm{~g}$ $\mathrm{NaCl}^{-1}$ soil solution). The entire gradient spans about $5 \mathrm{~km}$, and shows a gradual increase in salinity from non-saline to saline conditions.

We have sampled the soil community of the green beach along the salinity gradient. The dynamic nature of green beaches was reflected in the composition of the soil food web, which was rather simple, with only a limited number of 
numerically important species at each trophic level (Fig. 1). Microbial mats, mixed with unicellular algae were at the basis of the food web and provide subsequent trophic levels with energy and nutrients (Van Wingerden et al. 1981). Of all soil arthropods, $89 \%$ were Collembola ( 8 species), which make them by far the most dominant first order consumers, and important key species for the structure and functioning of the ecosystem (Fig. 1). The two dominant species were Hypogastrura viatica, with densities up to 20.000 ind. $\mathrm{m}^{-2}$ (50.000 ind. $\mathrm{m}^{-2}$, in Van der Kraan 1973) and Isotoma riparia with 18.000 ind. $\mathrm{m}^{-2}$. H. viatica is a halophilous species, usually found in shore debris along the coast, in rotting seaweed and in sewage beds (Thibaud et al. 2004), but there are also some scarce inland records from wet habitat (Fjellberg 1998). H. viatica is adapted to regular flooding; individuals can float on the water surface, on which they can survive up to 70 days and quickly colonize emerging parts of the green beach after flooding (Van Wingerden et al. 1981; Witteveen 1986). The second dominant collembolan, $I$. riparia, is a strictly hydrophilous species (Witteveen 1986). It occurs in different damp sites, such as river banks, wet meadows, in bogs, on water plants (Potapov 2001), but also in salt marshes (personal observations). A third collembolan, Sminthurides malmgreni, is known to occur near the sea shore, it is particularly wide spread and common on and near fresh water (Bretfeld 1999). We have found two subdominant herbivores, the staphylinid beetle Bledius sp. and the snail Catinella arenaria. Together, they contributed 5.5\% to the total soil fauna abundance.

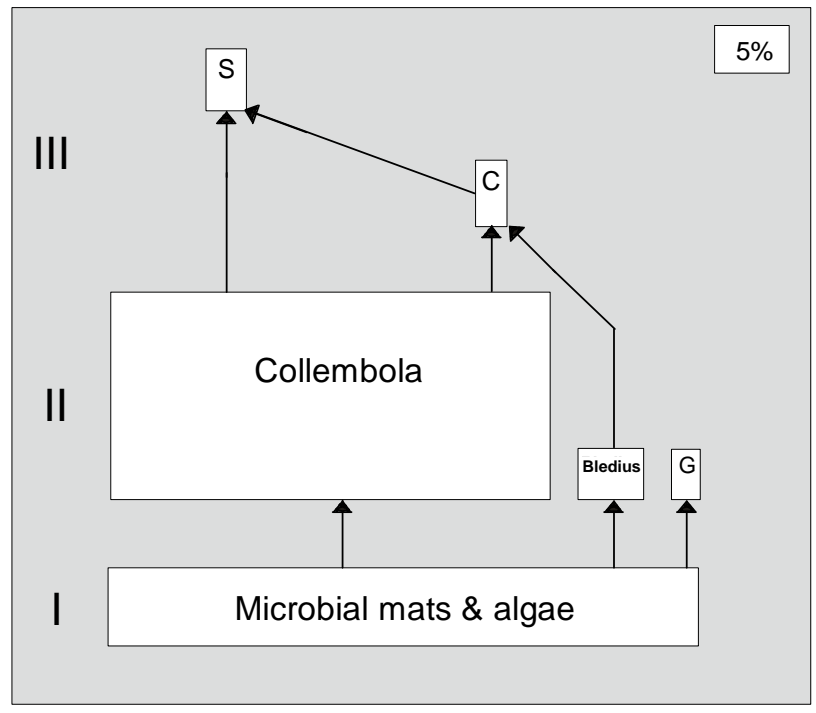

Fig. (1). Simplified connectedness food web depicting the most abundant ( $>1 \%$ of the total abundance) key species or species groups (boxes) that are found in the green beach soil community. Vectors indicate the trophic interactions among these organisms. Box sizes (see top right box for scale) depict differences in average total abundance of species over the salinity gradient (in July 2009), with the exception of the box microbial mats, which is significantly down-sized for convenience. Together, de faunal boxes comprise 98.3\% of all collected individuals. Abbreviations: G, Gastropoda; C, Carabid beetles; Bledius, Staphylinid beetle; S Spiders; I-III, trophic groups. For further explanation see text.

The most abundant second order consumers that live on the green beach were linyphid spiders, followed by lycosid spiders, and carabid beetles playing a minor role (Van Wingerden et al. 1981). The contribution of spiders to the total arthropod abundance was $2.1 \%$ (Fig. 1). The density of linyphid spiders reached a maximum of 300 ind. $\mathrm{m}^{-2}$, while the maximum density of lycosid spiders was around 100 ind. $\mathrm{m}^{-2}$. Both spider families prey mainly on Collembola, but they seem to differ in their choice of prey species. Linyphid spiders are small and prey mainly on $H$. viatica, while the larger lycosid spiders prefer I. riparia (Van Wingerden et al. 1981). Prey availability is one of the key factors that determine spider population density on the green beach (van Wingerden et al. 1981).

Although green beaches are rather uncommon, they are exemplary for many other types of ecosystem with similar environmental conditions, such as salt marshes, low elevation tundra and taiga, systems with regular dry and cold spells, such as unproductive sub-alpine and sub-arctic grasslands, or ecosystems that are highly dominated by a limited number of soil fauna species. Therefore, the green beach can serve as a model system and the conclusions derived from the comparison with our model predictions might be applicable to other ecosystems.

\section{Collection of Field Data}

We have sampled the soil community of the green beach at 6 sample points, with intervals of $1 \mathrm{~km}$ along the $5 \mathrm{~km}$ long salinity gradient. At each sample point $(20 \times 20 \mathrm{~m})$ we have estimated the densities of soil organisms using Perspex enclosures $(30 \times 30 \mathrm{~cm}$, pressed $3 \mathrm{~cm}$ into the soil, $\mathrm{n}=6)$. After enclosures were randomly placed, soil cores samples $(\varnothing$ $4 \mathrm{~cm}, 3 \mathrm{~cm}$ height, $\mathrm{n}=2$ ) were randomly taken within each enclosure to enable to count the numbers of the two small Collembola species $H$. viatica and $S$. malmgreni. Soil cores were transported to the field station in sealed plastic bags, submerged in a beaker filled with fresh water on arrival, after which the hydrophobic Collembola were scooped from the water surface and counted. After the soil cores were taken, the remaining soil fauna was collected using an exhauster until no more animals were observed in the enclosures for a period of 5 minutes. Collembola were determined to the species level, while the remaining species were grouped into families. All animal counts per sample point were expressed as the average number of individual per square meter.

The green beech salinity gradient and the corresponding tidal mark, located at the base of the inland dunes about 20 $\mathrm{m}$ behind the green beach were sampled in NovemberDecember 2008. We sampled the tidal mark a few days after an inundation event in December, when the green beech was fully submerged in seawater for the duration of one day. A second sampling of the green beech community took place in June-July 2009. Again, we sampled 6 replicates per sample point, with the exception of the first two saline sample points $(n=18)$, and the following two brackish sample points $(n=12)$ were more samples were taken to account for the sample point heterogeneity in vegetation composition.

\section{Habitat Preference Experiment}

The habitat preference of $H$. viatica was tested by their tendencies to settle in a gradient of soil salt contents from non-saline field conditions to saline field conditions, in 
absence of ecological interactions. In total 70 adult individuals, collected from the green beach (at brackish conditions) 18 days prior to testing and acclimatized at $16^{\circ} \mathrm{C}$ and $70 \% \mathrm{RH}$ in a climate room were individually released in a circular walkway $(\varnothing 12 \mathrm{~cm})$. The bottom of the walkway was divided into 16 compartments $(1.5 \times 2.5 \mathrm{~cm}$ each) filled with purified sand (see van Straalen \& Verhoef 1997 for a detailed drawing of the walkway). The salinity of the sand was adjusted using salt stock solutions of $2,15,30$, or $45 \mathrm{mg}$ $\mathrm{NaCl} 1^{-1}$. The four salt concentrations were layout in the circular walkway in four series, the order (randomly determined) of the salt contents fixed within the series. After 18 hours the location of each individual was noted. For each trial new walkways were prepared.

\section{MODEL DESCRIPTION}

To study the effect of community composition on performance of component species, we formulated a model comprising a target species whose abundance is constrained by predation and competition along an abiotic environmental gradient. Since including each competitor and predator species separately would be unfeasible for more complex communities, the model only incorporates their overall effect on the target species.

The model was formulated to loosely fit the general characteristics of the species occurring in the green beach community described above, but was not tailored to the biology of a particular species. The primary consumers in this beach system are Collembola, our target species, which are predated upon by various spider species. Laboratory studies on these and similar species, supplemented with literature data provide us with a biologically relevant range of life history variables to parameterise the model.

The target species was characterised by the following traits: initial weight $\left(w_{i}\right)$, weight at maturity $\left(w_{m}\right)$, individual growth rate $r$ and a salt response curve for growth rate. The parameters $w_{i}$ and $w_{m}$ were fixed for all scenario's (Table 1) and were derived from empirical data on growth curves and life history of Collembola, which show that individuals show exponential growth until reaching maturity after repeated moult cycles, after which growth rate slows down (Jansen \& Joosse 1987; Ernsting \& Isaaks 1997; Driessen et al. 2007). Salinity of the habitat varies among simulations from nonsaline to saline conditions $\left(S_{0-10}\right)$. Since only one salinity zone is used per simulation, the model contains no spatial structure. All salinity zones are assumed to have similar, constant, amounts of food available for the target species. In the model, the salt response curve describes the sensitivity of a species exponential growth rate to the salinity of the habitat. The salt response curve for growth rate can take three different forms: salt specialist, generalist, salt sensitive (Fig. 2a). Individuals with a salt specialist response curve show the highest growth rate in saline conditions and are unable to grow under non-saline conditions, whereas salt sensitive individuals show the opposite performance curve. A generalist response curve provides a constant growth rate independent of salinity. Exponential growth determines the body weight at time $\mathrm{t}$ according to $\mathrm{w}_{\mathrm{t}+1}=\mathrm{w}_{\mathrm{t}} \cdot e^{r}$, and an individual reaches maturity if $\mathrm{w}_{\mathrm{t}} \geq w_{m}$ (Driessen et al. 2007). A mature individual has a reproductive rate $m$ of one surviving offspring per time step. Net reproductive rate is generally low for springtails, with field-derived estimates around 0.55 and 1.29 (Van Straalen 1985), so we choose a reproductive rate of $m=1$. Each simulation lasts a fixed length of $t$ time steps and any individuals that have not reached maturity before the end of the season die without leaving offspring. In the absence of predators no intrinsic mortality is assumed, as predation is the major source of mortality (Van Straalen 1985).

Table 1. Parameterization of the Model

\begin{tabular}{|c|c|c|c|}
\hline Factor & Parameter & Value & Interpretation \\
\hline \hline $\begin{array}{c}\text { Habitat } \\
\text { salinity }\end{array}$ & $s$ & $0-10$ & $\begin{array}{c}\text { Non-saline to saline } \\
\text { conditions }\end{array}$ \\
\hline Initial weight & $w_{i}$ & 50 & Hatchling size in $\mu \mathrm{g}$ \\
\hline $\begin{array}{c}\text { Weight at } \\
\text { maturity }\end{array}$ & $w_{m}$ & 600 & Adult size in $\mu \mathrm{g}$ \\
\hline Growth rate & $r$ & $0-2$ & Exponential growth rate \\
\hline $\begin{array}{c}\text { Population } \\
\text { size }\end{array}$ & $p$ & 1000 & $\begin{array}{c}\text { Number of individuals in } \\
\text { one simulation }\end{array}$ \\
\hline $\begin{array}{c}\text { Season } \\
\text { length }\end{array}$ & $T$ & 10 & \begin{tabular}{c} 
Length of growing season \\
\hline $\begin{array}{c}\text { Reproductive } \\
\text { rate }\end{array}$
\end{tabular} \\
\hline $\begin{array}{c}\text { Competition } \\
\text { strength }\end{array}$ & $c$ & $0.05-1$ & $\begin{array}{c}\text { Weak to strong impact on } \\
\text { growth rate }\end{array}$ \\
\hline $\begin{array}{c}\text { Attack rate } \\
\text { offspring to next generation }\end{array}$ \\
\hline
\end{tabular}

Competitors and predators are also characterised by salt response curves, albeit for different traits, and we assume that the strength of their effect on the target species depends on salinity of the habitat. For competitors, the salt response curve reflects competition strength $c_{s}$, which negatively affects the growth rate $r$ of the target species following $r$. (1c) (Fig. 2b). The strength of competition can be thought of as a cumulative effect of the abundance and performance of all competitors. In its preferred habitat, competitors are assumed to be better able to obtain resources and hence reduce the growth efficiency of the target species through interference or scramble competition. For predators, the salt response curve reflects the attack rate $a$ (Fig. 2c), which reduces survival probability $l$ of the target species to $1-a$. The magnitude of the attack rate can be thought of as a cumulative effect of the abundance of all predators, and their performance given the salinity. Predators are assumed to be more active and hence catch more prey in their preferred habitat, resulting in an increased mortality risk for the target species. Predation probability is the only element of stochasticity in the model. For simplicity of the model, we assume competition strength and attack rate to be constant over time, and hence do not explicitly include independent population dynamics of competitors and predators.

For question 1, the model calculated two key performance traits for each salinity zone: the proportion of the target population that was able to survive to maturity and the average time to maturity. 


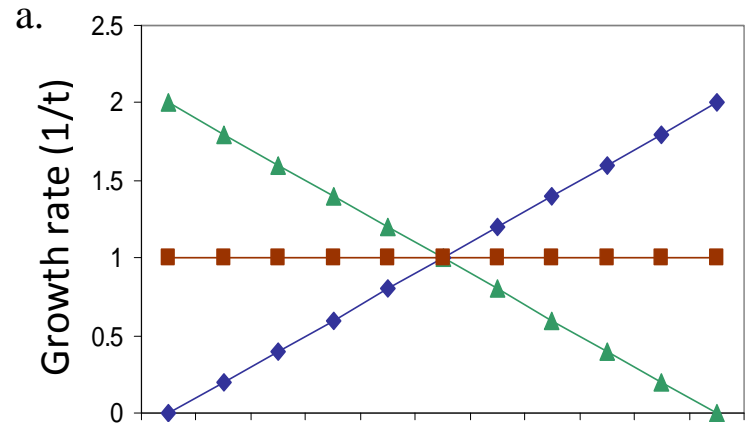

b.
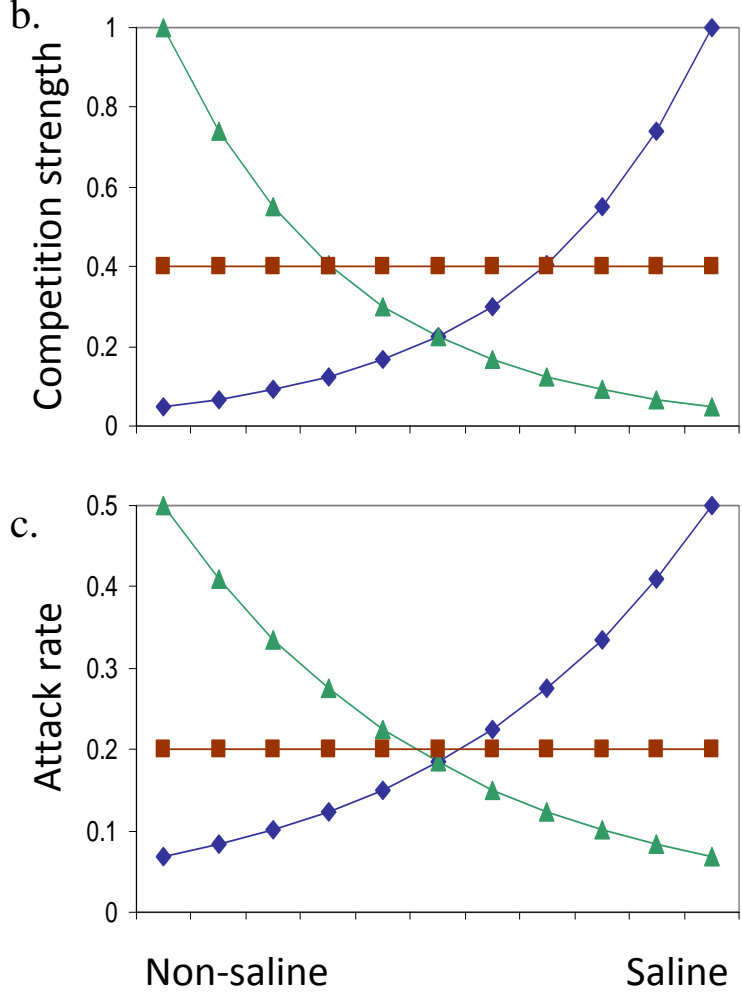

Fig. (2). Salt response curves for salt specialist (blue diamonds), generalist (brown squares), and salt sensitive (green triangles) species for, a) growth rate $r$ of the target species (salt specialist $r=$ $0.2 \cdot s$, generalist $r=1$, salt sensitive $r=0.2 \cdot(10-s)$ ); b) competition strength $c$ of the competitors (salt specialist $c=e^{-0.3 \cdot(10-\mathrm{s})}$, generalist $c=0.4$, salt sensitive $c=e^{-0.3 \cdot s}$ ); c) attack rate of the predators (salt specialist $a=0.5 \cdot e^{-0.2 \cdot(10-\mathrm{s})}$, generalist $a=0.2$, salt sensitive $a=$ $\left.0.5 \cdot e^{-0.2 \cdot \mathrm{s}}\right)$.

For question 2, pair-wise invasibility plots were produced that identify the interaction milieu under which successful invasion of the target species can occur. Successful invasion requires population growth rate of the invading species to be above unity. Therefore, population growth rate of the target species was calculated as the expected contribution of a single individual to the next generation. The expected contribution follows $\sum l_{x} \cdot m_{x}$ for $x=1$ to $t$. Changing the rate of reproduction $m$ would affect our conclusion quantitatively, but not qualitatively, as long as $m$ is the same for all salt performance curves. We calculated interaction milieu as the cumulative salt performance curves of predators and competitors. For this purpose we coded salt specialists as -1 , generalists as 0 , and salt sensitive species as 1 , leading to five interaction milieu values ranging from -2 to 2 . For ins- tance, if both predators and competitors were salt sensitive, the interaction milieu was 2 . Note that some values of the interaction milieu could be achieved with different combinations of predators and competitors performance curves; at these interaction milieu values the population growth rate was averaged across combinations.

\section{RESULTS}

\section{Can the Interaction Milieu Shift Species Performance Away from the Niche Optimum?}

We start by considering the case where there is no environmental dependence of biotic interactions. In this case, the predator and competitor are generalists; hence attack rate and competition strength are the same in all salinity conditions. Fig. (3a) shows the survival of the target species for three strategies across different salt conditions. There is a close correspondence between the salt response curve of the target species (its fundamental niche) and its performance in the community (its realised niche), which means that each strategy has the highest survival under the conditions at which its maximum growth rate is observed. The close match between growth rate and survival is a consequence of the fact that in the model the growth season is limited and individuals have to reach a size threshold to be able to survive to maturity.

With salinity-dependent variation in the interaction milieu, a precise match is no longer observed. The maximum growth rate is no longer a good predictor of survival because the interaction milieu modifies the performance of the target species. Fig. (3b) considers a community of a generalist predator and a salt-sensitive competitor, which has its maximum competition strength at low salinity. The presence of a specialist strategy in the community prevents high survival rates of the target species under non-saline conditions yet at the same time facilitates survival rates under salt conditions. As a result, for a generalist target species the highest survival is observed under saline conditions, erroneously suggesting that this is its preferred habitat like it is for a salt specialist (Fig. 3b).

Similarly, a salt-sensitive target species, with its maximum growth rate in non-saline habitats, now shows its peak in survival under intermediate salt conditions, because its growth rate is severely reduced under non-saline conditions by the high competition strength of the competitor species. This is also reflected in the salt-dependence of time to maturity of the target species. Maturity is reached twice as fast at intermediate salinities compared to the more extreme habitats, despite the fact that its salt response curve predicts it to perform best in fresh habitats.

An analogous result can be seen in a food web where the specialist strategy is adopted by the predator. Fig. (3c) considers a community of a generalist competitor and a saltsensitive predator, which has its maximum attack rate at low salinity. Again, survival of target species is much reduced at low salinities because predator attack rate is highest under these conditions. The target species shows the strongest shift from the fundamental niche if both predator and competitor are specialized at low salinities (Fig. 3d). Hence, it is not the identity or trophic position of the interacting species in the 
food web that determines selection on a target species, but rather the cumulative total of effect traits and strategies present in the community.

Field observations on the green beach ecosystem indicate that the interaction milieu can indeed shift species away from their fundamental niche. The abundance pattern along the salinity gradient showed that $S$. malmgreni was found only at the non-saline part of the gradient, I. riparia occurred along the whole gradient with a peak at intermediate salt conditions, and $H$. viatica had its highest abundance under saline conditions (Fig. 4a). The distribution data suggest that
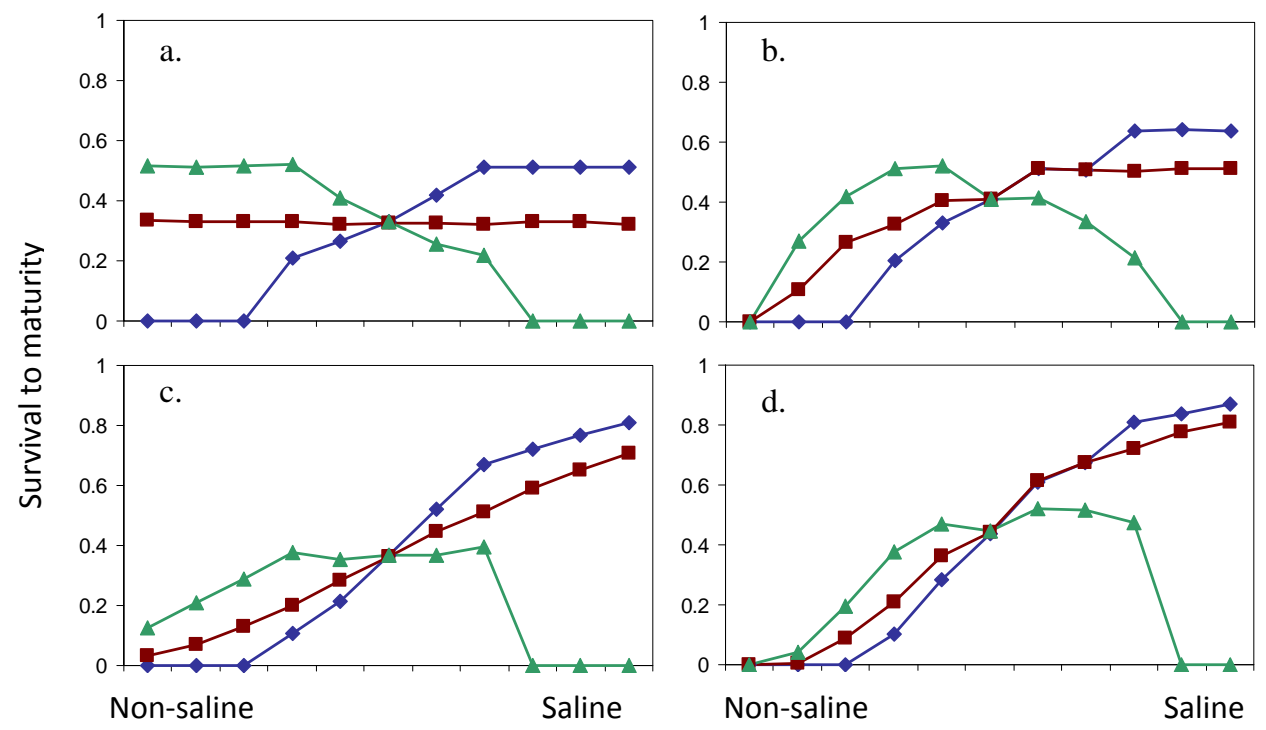

Fig. (3). Survival of the target species with different salt response curves when the interaction milieu consists of a) generalist predators and competitors; b) generalist predators and salt-sensitive competitors; c) salt-sensitive predators and generalist competitors; d) salt sensitive predators and competitors. The three lines represent three different salt strategies of the target species: salt specialist (blue diamonds), generalist (brown squares), salt-sensitive (green triangles).
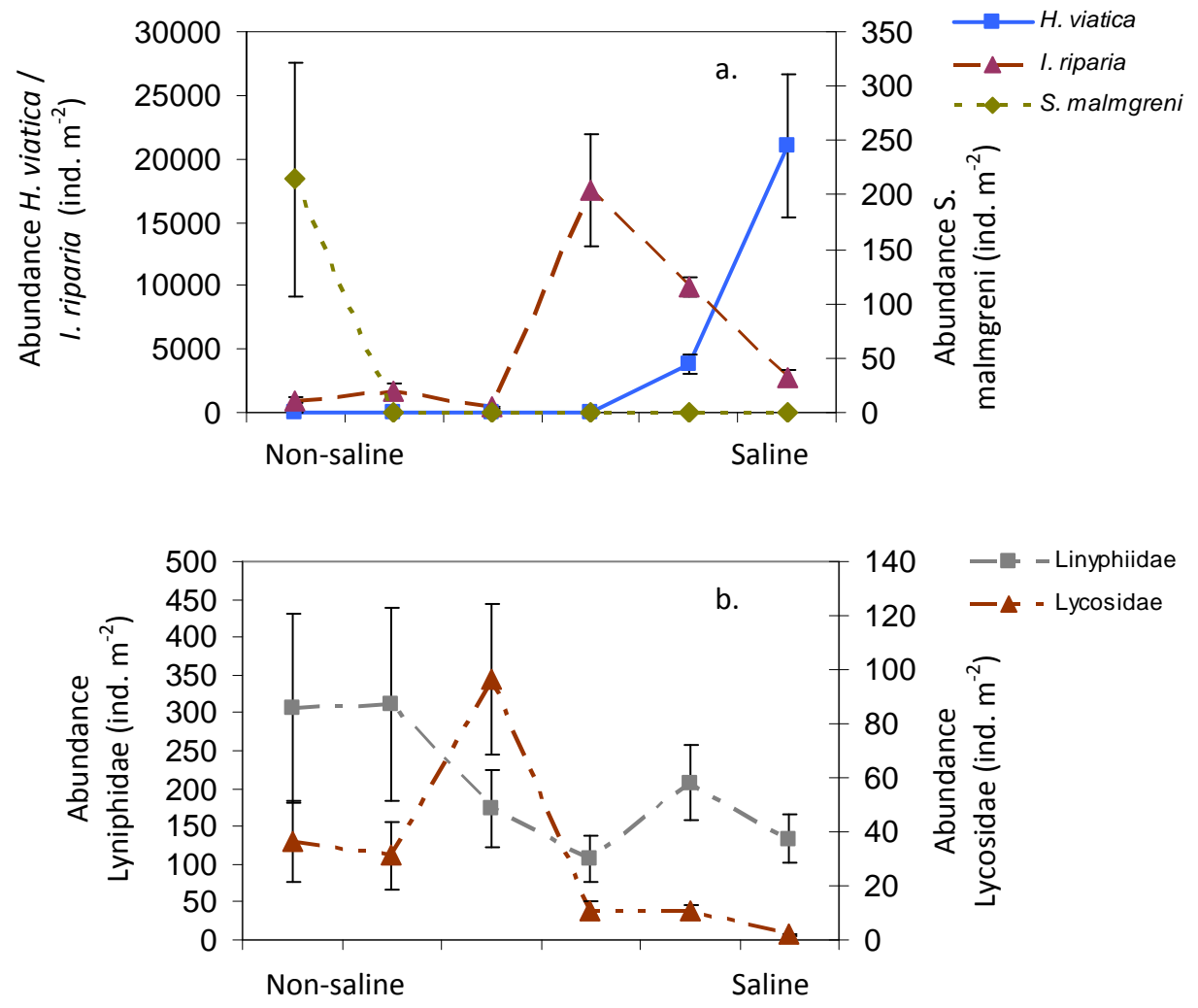

Fig. (4). Abundance (ind. $\mathrm{m}^{-2} \pm \mathrm{SE}, \mathrm{n}=6-18$ ) of three species of Collembola (a) and two spider families (b) over a salinity gradient on the green beach of Schiermonnikoog, in July 2009. The abundance of Isotoma riparia was multiplied by 5 to help graphical interpretation. 
S. malmgreni is salt sensitive, $I$. riparia is a generalist, and $H$. viatica is a salt specialist. However, when $H$. viatica was tested for its settling preference in absence of an interaction milieu it significantly preferred non-saline conditions, conforming a salt-sensitive species (Fig. 5). Hence, the abundance pattern of $H$. viatica under field conditions (Fig. 4a) showed a shift from its fundamental niche, probably due to the interaction milieu. According to our model, such a strong shift from the niche optimum is most likely to occur when the interaction milieu consists of salt-sensitive predators, and generalist (Fig. 3c) or salt-sensitive (Fig. 3d) competitors.

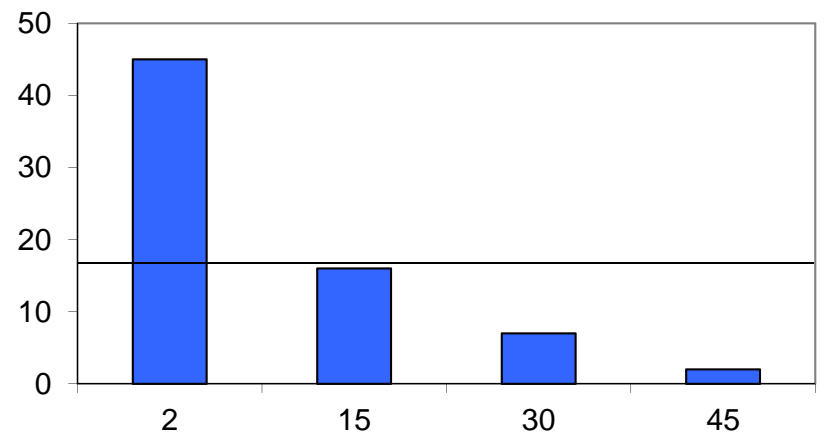

Fig. (5). The observed frequency distribution of the number of individuals of Hypogastrura viatica in a gradient of soil salt contents from non-saline to saline field conditions. The observed distribution deviates from the expected distribution in the absence of a preference (solid line) $\left(\chi^{2}\right.$-test $\mathrm{df}=3, P<0.1210^{-13}$ ).

Is there any evidence that $H$. viatica experiences such an interaction milieu on the green beach? Indeed, competition with the salt sensitive $S$. malmgreni and the generalist $I$. riparia may have resulted in the low abundance of $H$. viatica under non-saline conditions. Moreover, we observed the highest densities of linyphid and lycosid spiders under nonsaline conditions, although linyphids occurred along the entire salinity gradient.

Similarly, the peak in abundance of $I$. riparia under brackish conditions can be explained by the high density of predators under non-saline conditions, and competition with the highly abundant $H$. viatica under saline conditions. Experiments on the fundamental niche of $I$. riparia are necessary to establish if this species' distribution can also be explained by shifted species performance. The above example clearly demonstrates that omission of the interaction milieu from models that aim to predict future changes in community composition solely based on species performance response curves to an abiotic environmental gradient can lead to erroneous conclusions.

\section{Do Species with Divergent Trait Values Compared to the Interaction Milieu, have Higher Invasive Potential?}

The resident species community can be an important factor in constraining the ability of invasive species to establish. However, it may not be the number of species per se that is important but rather the trait space that is covered. Species that possess divergent trait values that enlarge the dissimilarity in the community are predicted to be at an advantage to invade. Fig. (6) shows that this prediction is generally confirmed by the model. For example, at low salinities, invasion of a salt-sensitive target species is only successful if the interaction milieu consists of salt tolerant species, with or without a generalist. Despite the fact that its maximum performance is at low salinity, a salt sensitive species cannot invade if a salt sensitive predator or competitor (or both) is present in the interaction milieu.

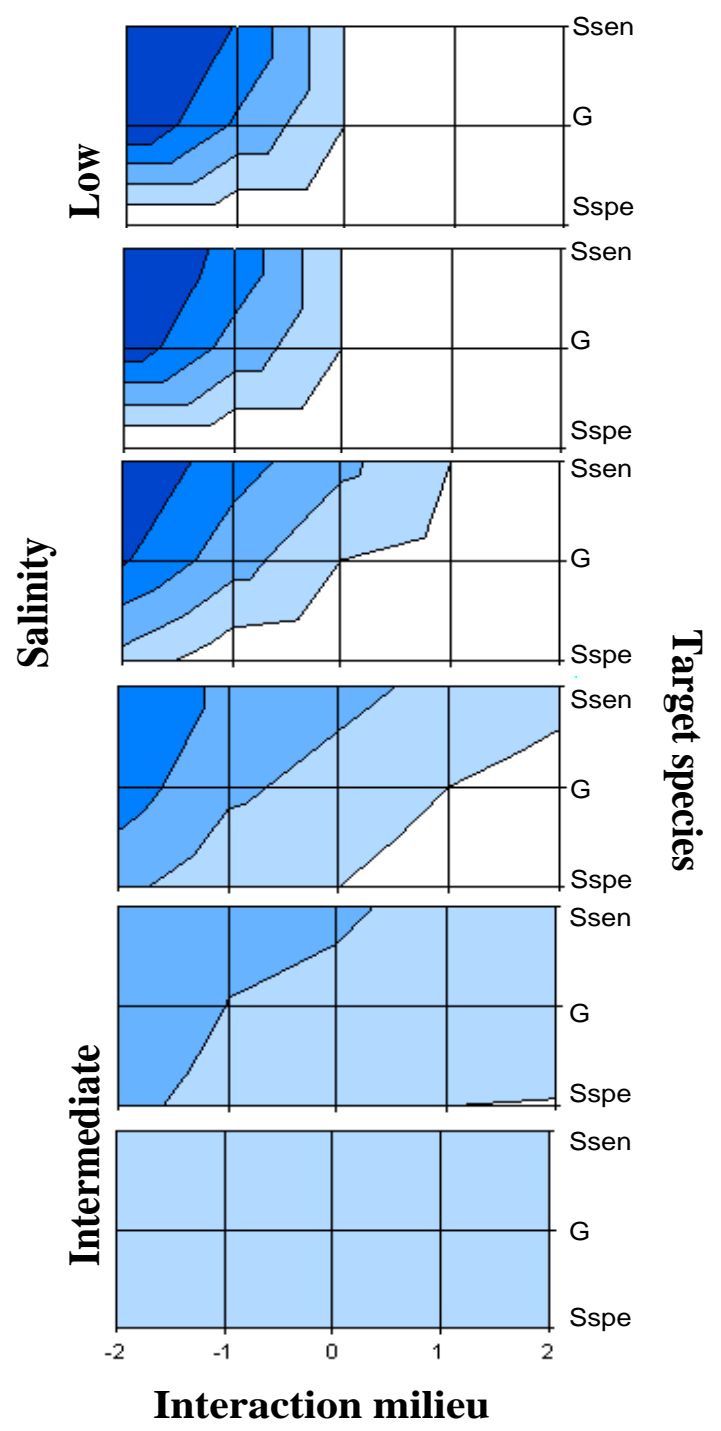

Fig. (6). Pair-wise invasibility plots of target species and interaction milieu for five different salinity conditions. The target species has different salt response curves: salt specialist (Sspe), generalist $(\mathrm{G})$ or salt sensitive (Ssen). The interaction milieu reflects the cumulative salt response curves of predators and competitors, coded as salt specialist: -1 , generalist: 0 , and salt sensitive: 1 , leading to five interaction milieu values ranging from -2 to 2 . White regions denote regions that are not invasible to the target species, as growth rate is below one, blue regions denote regions that are invasible as population growth rate is above one (isoclines indicate 1 unit increase of growth rate). When model predictions were not uniform for a combination of interaction milieu and target species, the growth rate was set to one. 
Moreover, there is an interaction effect with the salinity of the habitat. As can be expected, non-saline environments are such unsuitable habitat for salt specialist species that invasion is prevented, independent of the salt strategies present interaction milieu (Fig. 6). Also under non-saline conditions, the presence of two salt-sensitive species in the interaction milieu increases the competition and predation pressure to the extent that all salt performance strategies fail to invade. Vice versa, at intermediate salinity, competition and predation pressure is relatively low, and all salt performance strategies can invade each interaction milieu. In this case, it is difficult to predict which strategy will eventually invade since this may depend on stochastic factors or on other niche dimensions that have not been explicitly considered in the model.

Model predictions on invasibility as a function of the trait space of invasive species were supported by our field observations. An inundation event in the autumn of 2008 strongly modified the interaction milieu of the green beach, especially at the non-saline part of the salinity gradient. The diversity of collembolans was reduced to two species only, due to loss of species under non-saline conditions, while the abundance of generalist and salt-tolerant species was reduced by approximately $80 \%$ (Fig. 7a). Also, we observed a strong decline in the abundance of linyphid spiders under nonsaline conditions (Fig. 7b). The model predicts that under these circumstances salt-sensitive target species may invade, because the changes in interaction milieu make niche space available at low salinity. The tidal mark, which is bordering the green beach, is the main source of species invasions. Sminthurus malmgreni was the dominant salt-sensitive species in the tidal mark (Fig. 7c), and half a year after the inundation event this target species had invaded the nonsaline part of the green beach (Fig. 4a). This species not only differs in salt tolerance compared to I. riparia and H. viatica, but is also dissimilar in other traits, such as body size
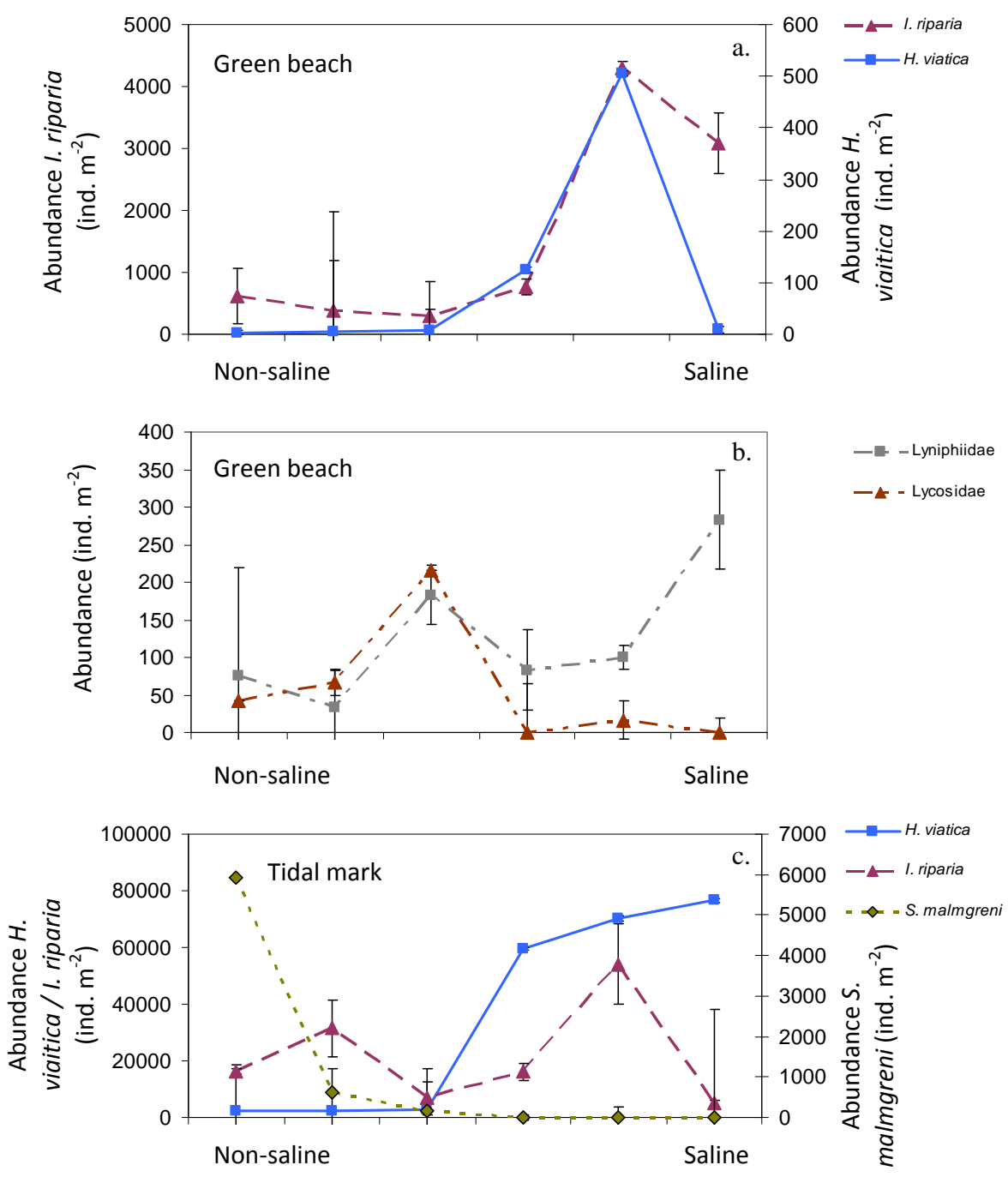

Fig. (7). Abundance (ind. $\mathrm{m}^{-2}+-\mathrm{SE}, \mathrm{n}=6$ ) of Collembola (a) and spiders (b) at the green beach ecosystem, and Collembola in the tidal mark (c). a) Collembola densities were rather low, as specimens were washed out from the green beach. Compare this figure with Fig. (4a). b) Spiders were not washed out from the green beach, with the exception of linyphid spiders. Their density was significantly reduced under non-saline conditions. Compare the densities in this figure with Fig. (4b). c) Collembola densities were high in the tidal mark. The tidal mark may serve as a source for colonisation after inundation events. Note the similarity in the distribution pattern in Fig. (4a) and in the tidal mark. 
(small), body form (globular), drought and heat tolerance (summer diapause), and diet choice (predominantly a herbivore), which might have facilitated its invasion.

Interestingly, during our field surveys we have observed seven target species that are potentially able to invade under non-saline conditions, while on average only two saltsensitive species occurred at low soil salt contents. This observation agrees with our model prediction that presence of two or more salt-sensitive species in the interaction milieu can increase the level of competition to the extent that other species, independent of their salt performance strategies fail to invade.

\section{DISCUSSION}

\section{How to Incorporate Genetic Diversity into Models of Species Interactions}

There is a growing consensus that considering genetic variation in traits of individuals and species is essential to understand and predict community dynamics (Agrawal et al. 2007; Johnson and Stinchcombe 2007; Ellers 2010). Several theoretical and empirical studies have shown evolutionary processes to determine community structure and composition (Bell 2007; Becks et al. 2010). Equally important but less recognized, is the role of community composition as a selective force shaping genetic and phenotypic variation at the individual level. Most evolutionary studies perform experiments with single species in isolation, or only in direct interaction with another species. Including interaction milieu as an ecological context for evolution may increase our understanding of the maintenance of genotypic diversity in the field. For example in our model we could assume the three salt response curves to exist as genotypic variation within the target species and test how a generalist or specialist interaction milieu affects genotypic diversity of target species along the salinity gradient. However, empirical data to validate such predictions are hardly available. Future field studies can alleviate this need by quantifying genetic variation in target species in different community compositions.

\section{How to Extend the Concept of Interaction Milieu to More Complex Communities?}

We showed that the concept of interaction milieu provides a general framework to understand how interaction between the biotic and abiotic contexts affect community assembly and shapes community structure due to shifts in species performances. The use of species traits will also help to place community composition as an essential component of the selective forces determining genetic and phenotypic variation at the individual level (Ellers 2010). However, the study system that we have used to validate model predictions represents a relatively simple example of a food web, with a limited number of interactions and, for a soil system, rather short food chains. Thus, the applicability of the interaction milieu concept should also be validated in more complex ecosystems. More complex food webs (e.g., with strong intraguild predation) and indirect interactions (e.g., apparent competition) can lead to unexpected effects on performance of component species (Bondavalli and Ulanowicz 1999; Wootton 2002). Moreover, food webs also differ greatly in how long food chains extend. Species interactions have been reported for up to five trophic levels (Harvey et al. 2009; Olff et al. 2009), with no evidence that the strength of the interaction wanes at higher trophic levels (Harvey et al. 2008). The interaction milieu concept simplifies the assemblage of competitors or predators within a community by concatenating all of those negative effects into an overall effect. The key to being able to utilize this approach in a complex system is the ability to: i) identify relevant response traits to environment, predation and competition (e.g, salt tolerance, body size, consumption rate, walking speed), ii) measure these traits and produce community weighted averages, iii) predict if a new species with a specific set of traits or with divergent trait values should be able to colonize, given the community weighted average and range for these traits, iv) test it with introduction experiments, and v) determine how all of the above influence direct and indirect effects (e.g. trophic cascades). Future theoretical and experimental studies should explore if the concept of interaction milieu can be generalized across trophic levels, and search for trophic and non-trophic traits that are important on deciding the outcome of ecological interactions. Furthermore, the identification of the relevant response traits and their frequency distribution, in combination with trait plasticity of species in interaction milieus might be a step forward to link evolutionary principles to ecological networks, and visa versa.

\section{CONCLUDING REMARKS}

Our model yielded testable and ecologically relevant predictions that were confirmed by field observations on the green beach ecosystem. First, we showed that interaction milieu can displace species from their fundamental-niche optimum. This led to abundance patterns that cannot be predicted by species performance response curves alone, showing the importance to include ecological interactions when modelling species distributions and responses to environmental changes (Berg et al. 2010). Second, the possibility of a given species to invade the community strongly depended on the interaction milieu. Species failed to invade their preferred part of the gradient if predators or competitors shared the same preference. This prediction of our model is substantiated by studies showing that successful invaders often have different attributes compared to resident species (Funk et al. 2008), or that higher trait plasticity enables invaders to adjust to a large range of environmental conditions (Berg \& Ellers 2010).

\section{ACKNOWLEDGEMENTS}

We would like to thank R. van Oosten, F. Heres Diddens, N. Hijner, and L. Meeuwissen for their field assistance. Herman Verhoef provided helpful comments on previous versions of the manuscript. A.T.C. Dias was financed by NWO postdoctoral grant number NWO / 819.01.017.

\section{REFERENCES}

Agrawal, AA, Ackerly, DD, Adler, F, Arnold, AE, Caceres, C, Doak, DF, Post, E, Hudson, PJ, Maron, J, Mooney, KA, Power, M, Schemske, D, Stachowicz, J, Strauss, S, Turner, MG \& Werner, E (2007) 
Filling key gaps in population and community ecology. Frontiers in Ecology and the Environment, 5, 145-52.

Bascompte, J, Jordano, P, Melián, CJ \& Olesen, JM (2003) The nested assembly of plant-animal mutualistic networks. Proceeds of the National Academy of Science of the USA, 100, 9383-7.

Berg, MP \& Ellers, J (2010) Trait plasticity in species interactions: A driving force of community dynamics. Evolutionary Ecology, 24, $617-29$.

Berg, MP, Kiers, ET, Driessen, G, van der Heijden, M, Kooi, BW, Kuenen, F, Liefting, M, Verhoef, HA \& Ellers, J (2010) Adapt or disperse: understanding species persistence in a changing world. Global Change Biology, 16, 587-98.

Berlow, EL, Neutel, A-M, Cohen, JE, De Ruiter, PC, Ebenman, B, Emmerson, M, Fox, JW, Janse, VAA, Jones, JI, Kokkoris, GD, Logofet, DO, McKane, AJ, Montoya, JM, \& Petchey, O (2004) Interaction strengths in food webs: issues and opportunities. Journal of Animal Ecology, 73, 585-98.

Bondavalli, C \& Ulanowicz, RE (1999) Unexpected effects of predators upon their prey: The case of the American alligator. Ecosystems, 2, $49-63$.

Bretfeld, G (1999) Synopsis on Palaearctic Collembola: Symphypleona. Abhandlungen und Berichte Naturkundemuseum Görlitz, 71, 1-318.

Brose, U \& Dunne, JA (2009) Modelling the dynamics of complex food webs. In: Verhoef, HA \& Morin, PJ (Eds.) Community ecology: Processes, models, and applications. Oxford University Press: Oxford.

Brown, AC \& McLachlan, A (1990) Ecology of sandy shores, Elsevier: Amsterdam

Buckley, LB \& Roughgarden, J (2005) Effect of species interactions on landscape abundance patterns. Journal of Animal Ecology, 74, 1182-94.

Davis, AJ, Lawton, JH, Shorrocks, B \& Jenkinson, LS (1998) Individualistic species responses invalidate simple physiological models of community dynamics under global environmental change. Journal of Animal Ecology, 67, 600-12.

Driessen, G, Ellers, J \& Van Straalen, NM (2007) Variation, selection and heritability of thermal reaction norms for juvenile growth in Orchesella cincta (Collembola: Entomobryidae). European Journal of Entomology, 104, 39-46.

Eichenberger, B, Siegenthaler, E \& Schmidt-Entling, MH (2009) Body size determines the outcome of competition for webs among alien and native sheetweb spiders (Araneae: Linyphiidae). Ecological Entomology, 34, 363-8.

Ellers, J (2010) Evolutionary processes in community ecology. In: Verhoef, HA \& Morin, PJ (Eds.) Community ecology: Processes, models, and applications. Oxford University Press: Oxford.

Emmerson, MC \& Raffaelli, D (2004) Predator-prey body size, interaction strength and the stability of a real food web. Journal of Animal Ecology, 73, 399-409.

Ernsting, G \& Issaks, JA (1997) Effect of temperature and season on egg size, hatchling size and adult size in Notiophilus biguttatus. Ecological Entomology, 22, 32-40.

Falster, DS \& Westoby, M (2003) Plant height and evolutionary games. Trends in Ecology \& Evolution, 18, 337-43.

Fjellberg, A (1998) Collembola of Fennoscandia and Denmark, part 1: Poduromorpha. Fauna Entomologica Scandinavica, 35, 1-183.

Funk, JL, Cleland, EE, Suding, KN \& Zavaleta, ES (2008) Restoration through reassembly: Plant traits and invasion resistance. Trends in Ecology \& Evolution, 23, 695-703.

Funk, JL \& Vitousek, PM (2007) Resource-use efficiency and plant invasion in low-resource systems. Nature, 446, 1079-81.

Gause, GF (1936) The struggle for existence, Williams and Wilkins: Baltimore.

Grime, JP (2006) Trait convergence and trait divergence in herbaceous plant communities: Mechanisms and consequences. Journal of Vegetation Science, 17, 255-60.

Harvey, JA, Bezemer, TM, Gols, R, Nakamatsu, Y \& Tanaka, T (2008) Comparing the physiological effects and function of larval feeding in closely-related endoparasitoids (Braconidae : Microgastrinae) Physiological Entomology, 33, 217-25.

Harvey, JA, Wagenaar, R \& Bezemer, TM (2009) Interactions to the fifth trophic level: Secondary and tertiary parasitoid wasps show extraordinary efficiency in utilizing host resources. Journal of Animal Ecology, 78, 686-92.

Janssen, GM \& Joosse, ENG (1987) Reproduction and growth of Collembola in laboratory conditions. Pedobiologia, 30, 1-9.

Jiang, L \& Morin, PJ (2004) Temperature-dependent interactions explain unexpected responses to environmental warming in communities of competitors. Journal of Animal Ecology, 73, 569-76.

Johnson, MTJ \& Stinchcombe, JR (2007) An emerging synthesis between community ecology and evolutionary biology. Trends in Ecology \& Evolution, 22, 250-7.

Johnson, NC, Graham, JH \& Smith, FA (1997) Functioning of mycorrhizal associations along the mutualism-parasitism continuum. New Phytologist, 135, 575-86.

Lawton, JH (1999) Are there general laws in ecology? Oikos, 84, 177-92.

Lockwood, DR (2008) When logic fails ecology. Quarterly Review of Biology, 83, 57-64.

McGill, BJ, Enquist, BJ, Weiher, E \& Westoby, M (2006) Rebuilding community ecology from functional traits. Trends in Ecology \& Evolution, 21, 178-85.

Moran, MD \& Hurd, LE (1998) A trophic cascade in a diverse arthropod community caused by a generalist arthropod predator. Oecologia, $113,126-32$.

Olff, H, Alonso, D, Berg, MP, Eriksson, BK, Loreau, M, Piersma, T \& Rooney, N (2009) Parallel ecological networks in ecosystems. Philosophical Transactions of the Royal Society B, 364, 1755-79.

Potapov, M (2001) Synopsis on Palaearctic Collembola: Isotomidae. Abhandlungen und Berichte Naturkundemuseum Görlitz, 73, 1-603.

Reiss, J, Bridle, JR, Montoya, JM \& Woodward, G (2009) Emerging horizons in biodiversity and ecosystem functioning research. Trends in Ecology and Evolution, 24, 505-14.

Romanuk, TN, Zhou, Y, Brose, U, Berlow, EL, Williams, RJ \& Martinez, ND (2009) Predicting invasion success in complex ecological networks. Philosophical Transactions of the Royal Society B, 364, 1743-54.

Simberloff, D (2004) Community ecology: Is it time to move on? American Naturalist, 163, 787-99.

Thibaud, JM, Schulz, HJ \& da Gama Assalino, MM (2004) Synopsis on Palaearctic Collembola: Hypogastruridae. Abhandlungen und Berichte Naturkundemuseum Görlitz, 75, 1-287.

Van Straalen, NM (1985) Comparative demography of forest floor Collembola populations. Oikos, 45, 253-65.

Van Straalen, NM (1989) Production and biomass turnover in 2 populations of forest floor collembola. Netherlands Journal of Zoology, 39, 156-68.

Van Wingerden, WKRE, Littel, A \& Boomsma, JJ (1981) Strategies and population dynamics of arthropod species from coastal plains and green beaches. In: Smit, JC, den Hollander, JE, WKRE van Wingerden \& Wolff, JE (Eds.) Terrestrial and freshwater fauna of the Wadden Sea., Wadden Sea Working Group: Leiden.

Violle, C, Navas, ML, Vile, D, Kazakou, E, Fortunel, C, Hummel, I \& Garnier, E (2007) Let the concept of trait be functional! Oikos, 116, 882-92.

Weiher, E, Clarke, GDP \& Keddy, PA (1998) Community assembly rules, morphological dispersion, and the coexistence of plant species. Oikos, 81, 309-22.

Witteveen, J (1986) Marine littoral Collembola. Thesis, VU University Amsterdam.

Wood, SA, Lilley, SA, Schiel, DR \& Shurin, JB (2010) Organismal traits are more important than environment for species interactions in the intertidal zone. Ecology Letters, 13, 1160-71.

Wootton, JT (2002) Indirect effects in complex ecosystems: Recent progress and future challenges. Journal of Sea Research, 48, 157-72. 